\title{
The Prevalence of Neuropathy and Relationship with Risk Factors in Diabetic Patients: A Single-Center Experience
}

\author{
Ali Tamer ${ }^{\mathrm{a}}$ Serpil Yildiz $^{\mathrm{b}}$ Nebil Yildiz $^{\mathrm{b}}$ Mustafa Kanat ${ }^{\mathrm{a}}$ Huseyin Gunduz $^{\mathrm{c}}$ \\ Mustafa Tahtaci ${ }^{\mathrm{a}}$ Harika Celebi $^{\mathrm{a}}$ \\ Departments of ${ }^{\mathrm{a}}$ Internal Medicine, ${ }^{\mathrm{b}}$ Neurology and ${ }^{\mathrm{c}}$ Cardiology, Izzet Baysal Faculty of Medicine, \\ Abant Izzet Baysal University, Bolu, Turkey
}

\author{
Key Words \\ Diabetes mellitus · Peripheral neuropathy • \\ Polyneuropathy
}

\begin{abstract}
Objective: To determine the rate of distal symmetrical polyneuropathy (DSP) in patients with type 2 diabetes mellitus, to evaluate the role of history, neurological examination and the electrodiagnostic methods in the diagnosis of DSP, and to determine the association between electromyography-supported neuropathy (ESN), neuropathic complaints (NCs) and risk factors. Subjects and Methods: A total of 191 type 2 DM patients (109 female, 82 male; mean age $58.7 \pm 10$ years) were recruited. The NCs were recorded. All patients had electromyographic (EMG) examinations. The relationship between ESN, NCs and risk factors were evaluated. Results: Of the 191 patients, 83 (43.5\%) had DSP on EMG examinations and $92(48.2 \%)$ patients suffered from NCs. Among the ESN patients, a significant relationship existed with $\mathrm{HbA} 1_{\mathrm{c}}$ level, illness duration, smoking, male gender or insulin usage $(p<0.05)$ but not with age, hypertension, hypercholesterolemia or hypertriglyceridemia. The frequency of NCs was higher in patients with ESN. There was also a significant association between NCs and ESN $(p<0.05)$. The presence of NCs was not related to age, gender, smoking, hypertension, hypercholesterolemia and hypertriglyceridemia $(p>0.05)$ but NCs were corre-
\end{abstract}

lated to $\mathrm{HbA} 1_{\mathrm{c}}$ level, illness duration and insulin usage $(p<0.05)$. Conclusion: Our data show that a strong association exists between the presence of DSP and illness duration, $\mathrm{HbA} 1_{\mathrm{c}}$, smoking, thereby indicating that cessation of smoking and near normal glycemic control would be additional precautions to delay the beginning or progression of polyneuropathy.

Copyright (C) 2006 S. Karger AG, Basel

\section{Introduction}

Diabetes mellitus (DM) is a metabolic disorder characterized by abnormal carbohydrate metabolism. DM increases the risk of arteriosclerosis and development of microvascular and neurological complications. Diabetic distal symmetrical polyneuropathy (DSP) is the most common cause of peripheral neuropathy in developed countries [1]. DSP is not a single entity and includes a number of different syndromes. The most frequent disorder of the peripheral nervous system in diabetic patients is a DSP that not only predominantly involves the sensory fibers in the legs but also motor and autonomic fibers, leading to progressive degeneration with loss of nerve fibers [1]. Focal or multifocal neuropathies and less frequently truncal neuropathy, radiculopathy and proximal diabetic neuropathy may also occur [2].

The pathophysiology of diabetic neuropathy is multifactorial (genetic, environmental, behavioral, metabolic,

\section{KARGER}

Fax +4161306 1234

E-Mail karger@karger.ch

www.karger.com
(C) 2006 S. Karger AG, Basel

$1011-7571 / 06 / 0153-0190 \$ 23.50 / 0$

Accessible online at:

www.karger.com/mpp
Dr. Ali Tamer

Eski Istanbul Caddesi, Bahcelievler Mahallesi

Karsu Apartmani 11/4

TR-14070 Bolu (Turkey)

Tel. +90374215 9695, Fax +90 374217 5061, E-Mail atamer2002@yahoo.com 
neurotrophic, and vascular) [3]. Smoking, duration of $\mathrm{DM}$, high serum levels of $\mathrm{HbA} 1_{c}$ and low serum levels of high-density lipoprotein cholesterol increase the risk of neuropathy [4]. Immune disorder may be responsible for the clinical neuropathic syndrome, especially in those with proximal neuropathy and those with a more marked motor component. Progression of diabetic neuropathy is related to glycemic control in both type 1 and type $2 \mathrm{DM}$ [5]. Subclinical neuropathy is determined by abnormalities in electrodiagnostic and quantitative sensory testing. It is important to identify subclinical neuropathy before the clinical findings appear because the patients may respond better to an early treatment if the condition is diagnosed early [6].

Hence, the aim of this study was to determine the rate of DSP in patients with type $2 \mathrm{DM}$, to evaluate the role of history, neurological examination and the electrodiagnostic methods in the diagnosis of DSP, and to determine the relationship between electromyography-supported neuropathy (ESN), neuropathic complaints (NCs) and risk factors.

\section{Subjects and Methods}

\section{Subjects}

A total of 191 type $2 \mathrm{DM}$ patients (109 female and 82 male) were recruited; mean age was $58.7 \pm 10$ years. The study was approved by the Ethics Committee and informed consent was obtained. Parameters such as age, smoking, duration of illness, the presence of hypertension (HT), and drug usage were recorded and neurologic examination was performed. NCs such as numbness, weakness, pain and sensation of needle were recorded. 'Cold feeling in the feet', 'stinging and pricking', 'cramping of gastrocnemius', 'feeling as if a piece of paper is attached to the sole of the feet', 'tingling sensation in the feet' and 'burning sensation in the feet' were accepted as NCs. Peripheral neuropathy was diagnosed clinically by vibratory, pinprick, temperature sensation and tendon reflex abnormalities. Electromyographic (EMG) examination was performed using a Nicolet Viking Select IV Channel EMG machine. Motor and sensory conduction studies in lower extremities and one upper extremity (if necessary, the other one also), tibial F responses and soleus muscle $\mathrm{H}$ reflexes were recorded. The obtained values of the nerve conduction velocity (NCV) were compared with normal values of our laboratory.

$\mathrm{NCV}$ values less than $40 \mathrm{~m} / \mathrm{s}$ for lower and $50 \mathrm{~m} / \mathrm{s}$ for upper extremities were considered as abnormal. Sural sensory nerve action potential amplitudes less than $9 \mu \mathrm{V}$, median and ulnar sensory nerve action potential amplitudes less than $10 \mu \mathrm{V}$ were deemed as abnormal. The $\mathrm{F}$ wave latencies and $\mathrm{H}$ reflex latencies were compared with the height-adjusted normal values given by $\mathrm{Oh}$ [7].

EMG examinations were used to diagnose DSP, the level of which was classified as mild, moderate or severe: (1) mild: one or two abnormalities - mild decrease in motor and/or sensory NCV, loss or decrease of amplitude of the sural nerve sensory response, delay in tibial F response, loss or delay of soleus H reflex; (2) moderate: more than two abnormalities - mild to moderate decrease in motor NCV, the loss of sural nerve sensory responses, decrease of the tibial and/or peroneal motor responses, mild decrease in motor and/or sensory NCV and mild decrease of amplitude of the distal sensory responses at upper extremities; (3) severe: abnormalities in all parameters - having severer abnormalities than those mentioned in moderate polyneuropathy, severe decrease in amplitudes of tibial and peroneal motor responses, mild to moderate decrease in motor and sensory NCV and moderate decrease or loss of amplitude of the distal sensory responses at upper extremities, neurogenic changes in distal muscles of the lower extremities in needle EMG.

Patients using oral antidiabetic drugs and insulin or those with a plasma glucose level $\geq 200 \mathrm{mg} / \mathrm{dl} 2 \mathrm{~h}$ after an oral glucose tolerance test were diagnosed as diabetic. Patients with total cholesterol levels over $200 \mathrm{mg} / \mathrm{dl}$ or triglyceride levels over $150 \mathrm{mg} / \mathrm{dl}$ were diagnosed as hyperlipidemic. Patients with blood pressure over 140/90 mm Hg were considered hypertensive, including those taking antihypertensive medication. The cigarette-smoking patients were referred to as smokers. The subjects were classified as diabetic patients treated with diet only, oral antidiabetic or insulin. The duration of illness was presented in months. After $12 \mathrm{~h}$ of fasting, blood total cholesterol, triglyceride and $\mathrm{HbA} 1_{\mathrm{c}}$ levels were measured by the standard methods.

The subjects were also divided into four groups: ESN, normal EMG patients and those with and without NCs. The relationship between NCs, DSP and risk factors was evaluated.

\section{Exclusion Criteria}

Those patients with any other cause of peripheral neuropathy (malignancy, vascular disorder, connective tissue disease, inflammatory disorder, alcohol abuse), significant neurological disorders other than diabetic polyneuropathy (stroke, multiple sclerosis) and chronic renal failure were excluded.

\section{Statistical Analysis}

Statistical analysis was performed using the Statistics for Social Sciences (SPSS 10.0 for Windows) program. Quantitative values between two groups were compared by the Student t test and were given as means \pm standard deviation and percent change. Qualitative values were compared by the $\chi^{2}$ test. The association between the presence of ESN, presence of NCs and risk factors in diabetic patients was determined using multivariate stepwise logistic regression analysis. In all analyses, $\mathrm{p}<0.05$ was considered statistically significant.

\section{Results}

The clinical and laboratory profiles of the patients are summarized in table 1 . The mean value of serum level of $\mathrm{HbAl}_{\mathrm{c}}$ was $8.2 \pm 2.1 \%$. The mean illness duration was $90.6 \pm 84$ months. Of the 191 patients, $108(56.5 \%)$ had normal EMG while 83 (43.5\%) had ESN with DSP. The degree of neuropathy was as follows: mild 35 (42.2\%); moderate $41(49.4 \%)$, and severe 7 (8.4\%). 
Table 1. Clinical and laboratory characteristics of the patients

\begin{tabular}{lc}
\hline Normal electromyography & $108(56.5)$ \\
EMG-supported neuropathy & $83(43.5)$ \\
Degree of neuropathy & \\
$\quad$ Mild & $35(42.2)$ \\
$\quad$ Moderate & $41(49.4)$ \\
$\quad$ Severe & $7(8.4)$ \\
Hypertension & $78(40.8)$ \\
Total cholesterol, mg/dl & $212 \pm 43$ \\
Triglyceride, mg/dl & $185 \pm 125$ \\
Smoking & $54(28.2)$ \\
Drug usage & \\
$\quad$ Diet & $30(15.7)$ \\
Oral antidiabetic drug & $131(68.6)$ \\
$\quad$ Insulin & $30(15.7)$ \\
Neuropathic complaints & $92(48.2)$ \\
\hline
\end{tabular}

Figures in parentheses indicate percentages.

Seven patients (8.4\%) with ESN were normal on neurological examination (but with subclinical neuropathy). Ninety-two $(48.2 \%)$ patients had neurologic complaints: 37 of them had no abnormality on EMG examination, while 55 patients had ESN findings. ESN was also noted in 28 patients who did not have NCs. Sensitivity and specificity of NCs were 59 and $71 \%$, respectively.

Carpal tunnel syndrome was seen in 30 cases (16\%), cubital tunnel syndrome in 3 cases (2\%), carpal tunnel plus cubital tunnel syndromes in 1 case $(0.5 \%)$, truncal neuropathy in 2 cases (1\%) and anterior interosseous mononeuropathy in 1 case $(0.5 \%)$. Twenty of 31 patients with carpal tunnel syndrome and 1 of 4 patients with cubital tunnel syndrome had no abnormality in EMG other than entrapment neuropathy (table 2).

Male gender was associated with an increased risk for DSP $(p<0.05)$. In the ESN group, there was a significant relationship between blood level of $\mathrm{HbA} 1_{c}$, duration of illness, smoking and drug usage $(p<0.05)$ but not between DSP and age, HT, hypercholesterolemia, and hypertriglyceridemia $(p>0.05)$. The number of patients using insulin was higher in the ESN group than among those with normal EMG $(\mathrm{p}<0.05)$ (table 3). In the ESN group, multivariate logistic analysis showed increased blood level of $\mathrm{HbAl}_{\mathrm{c}}(\mathrm{OR}=1.034,95 \% \mathrm{CI}=1.014$ 1.054), longer duration of illness $(\mathrm{OR}=1.010,95 \% \mathrm{CI}=$ 1.004-1.015), more smoking $(\mathrm{OR}=2.330,95 \% \mathrm{CI}=$ $1.222-4.445)$, more males $(\mathrm{OR}=0.213,95 \% \mathrm{CI}=0.09$ $0.500)$ and increased insulin usage $(\mathrm{OR}=0.289,95 \%$ $\mathrm{CI}=0.87-0.961)$.
Table 2. Entrapment neuropathies in diabetic patients

\begin{tabular}{llll}
\hline & $\begin{array}{l}\text { Normal EMG } \\
(\mathrm{n}=108)\end{array}$ & $\begin{array}{l}\text { ESN } \\
(\mathrm{n}=83)\end{array}$ & $\begin{array}{l}\text { Total } \\
(\mathrm{n}=191)\end{array}$ \\
\hline Carpal tunnel syndrome & $20(18.5)$ & $11(13.2)$ & $31(16.2)$ \\
$\quad$ Female/male & $19 / 1$ & $9 / 2$ & $28 / 3$ \\
Cubital tunnel syndrome & $1(0.9)$ & $3(3.6)$ & $4(2)$ \\
$\quad$ Female/male & $1 / 0$ & $0 / 3$ & $1 / 3$ \\
Truncal neuropathy & $1(0.9)$ & $1(1.2)$ & $2(1)$ \\
$\quad$ Female/male & $0 / 1$ & $0 / 1$ & $0 / 2$ \\
Interosseous neuropathy & & $1(1.2)$ & $1(0.5)$ \\
$\quad$ Female/male & & $0 / 1$ & $0 / 1$ \\
Total & $22(20.3)$ & $16(19.2)$ & \\
$\quad$ Female/male & $20 / 2$ & $9 / 7$ & \\
\hline
\end{tabular}

Figures in parentheses indicate percentages.

Table 3. General characteristics of patients for the presence of ESN

\begin{tabular}{lccc}
\hline & $\begin{array}{l}\text { Normal } \\
\text { electromyography } \\
\text { group }(\mathrm{n}=108)\end{array}$ & $\begin{array}{l}\text { ESN group } \\
(\mathrm{n}=83)\end{array}$ & $\mathrm{p}$ \\
& $74 / 34$ & $35 / 48$ & $<0.05$ \\
\hline Female/male & $56.8 \pm 11$ & $61 \pm 10$ & $\mathrm{NS}$ \\
Age, years & $7.5 \pm 1.7$ & $9.1 \pm 2.2$ & $<0.01$ \\
$\mathrm{HbA1}_{\mathrm{c}}, \%$ & $59 \pm 63$ & $131 \pm 91$ & $<0.01$ \\
Illness duration, months & $44(40.7)$ & $34(41)$ & $\mathrm{NS}$ \\
Hypertension & $216 \pm 42$ & $206 \pm 43$ & $\mathrm{NS}$ \\
Total cholesterol, mg/dl & $189 \pm 149$ & $181 \pm 85$ & $\mathrm{NS}$ \\
Triglyceride, mg/dl & $23(21.3)$ & $31(37.4)$ & $<0.01$ \\
Smoking & & & \\
Drug usage & $25(23.1)$ & $5(6)$ & $<0.05$ \\
$\quad$ Diet & $78(72.2)$ & $53(63.9)$ & $\mathrm{NS}$ \\
$\quad$ Oral antidiabetic drug & $5(4.6)$ & $25(30.1)$ & $<0.05$ \\
$\quad$ Insulin & $37(34.3)$ & $55(66.3)$ & $<0.05$ \\
Neuropathic complaints & & &
\end{tabular}

NS = Not significant. Figures in parentheses indicate percentages.

The frequency of NCs was higher in the ESN group than in the EMG normal group $(p<0.05)$. This relationship was more pronounced in patients with moderate and severe polyneuropathy compared to those with mild polyneuropathy $(p<0.05)$. The presence of NCs was not related to age, gender, smoking, HT, hypercholesterolemia and hypertriglyceridemia $(\mathrm{p}>0.05)$ but it was correlated with blood $\mathrm{HbAl}_{\mathrm{c}}$ level, duration of illness and insulin usage $(\mathrm{p}<0.05)$ (table 4). 
Table 4. General characteristics of the patients for NCs

\begin{tabular}{lccc}
\hline & $\begin{array}{c}\text { NCs (-) } \\
(\mathrm{n}=99)\end{array}$ & $\begin{array}{c}\text { NCs (+) } \\
(\mathrm{n}=92)\end{array}$ & $\mathrm{p}$ \\
& $54 / 45$ & $55 / 37$ & $\mathrm{NS}$ \\
Female/male & $58.5 \pm 11$ & $59 \pm 10$ & $\mathrm{NS}$ \\
Age, years & $7.9 \pm 1.9$ & $8.5 \pm 2.3$ & $<0.05$ \\
HbA1, c & $62 \pm 75$ & $121 \pm 83$ & $<0.05$ \\
Illness duration, months & $71(71.7)$ & $37(40.2)$ & $<0.05$ \\
EMG normal & $28(28.3)$ & $55(59.8)$ & $<0.05$ \\
EMG-supported neuropathy & & & \\
Degree of neuropathy & $18(18.2)$ & $17(18.5)$ & $\mathrm{NS}$ \\
$\quad$ Mild & $9(9.1)$ & $32(34.8)$ & $<0.05$ \\
$\quad$ Moderate & $1(1)$ & $6(6.5)$ & $<0.05$ \\
$\quad$ Severe & $43(43.4)$ & $35(38)$ & $\mathrm{NS}$ \\
Hypertension & $212 \pm 42$ & $211 \pm 44$ & $\mathrm{NS}$ \\
Total cholesterol, mg/dl & $180 \pm 106$ & $192 \pm 143$ & $\mathrm{NS}$ \\
Triglyceride, mg/dl & $27(27.3)$ & $27(29.4)$ & $\mathrm{NS}$ \\
Smoking & & & \\
Drug usage & $23(23.2)$ & $7(7.6)$ & $<0.05$ \\
$\quad$ Diet & $66(66.6)$ & $65(70.7)$ & $\mathrm{NS}$ \\
$\quad$ Oral antidiabetic drug & $10(10.1)$ & $20(21.7)$ & $<0.05$ \\
$\quad$ Insulin & & & \\
\hline
\end{tabular}
ages.

NS $=$ Not significant. Figures in parentheses indicate percent-

\section{Discussion}

Diabetes is a common cause of DSP in the developed countries. The frequency of DSP is reported to be between 8 and $50 \%[8,9]$ but that of NCs is as high as $84.8 \%$ [10]. In the present study, while the frequency of NCs $(48.2 \%)$ is lower than in previous reports, the frequency of ESN (43.5\%) is within the reported rate. This discrepancy might be due to the high blood glucose levels during the EMG examination period, and because small fiber neuropathy, if present, could not be detected by standard EMG examinations [11].

The frequency of NCs in the ESN group was significantly higher in patients with moderate and severe polyneuropathy $(p<0.05)$; patients without NCs had mild polyneuropathy. These rates demonstrate that NCs should be considered important, and that mild polyneuropathy could develop without any indication of NCs. The present study also demonstrated that neurological examination is as important as EMG examination. Lowlevel sensory loss and hypoactivity of deep tendon reflexes were found in neurological examination in 7 patients whose EMG examinations were normal.

There are conflicting reports regarding the frequency of DSP with age, gender, HT and hyperlipidemia [8, 9,
12-14]. Generally, the frequency is higher in patients over 70 years. In our study, a significant relationship between ESN and gender was noted, but not with age, HT and total cholesterol or triglyceride levels. Poor glycemic control and duration of diabetes has a major role in the development of the complications of DM. The severity of DSP is strongly linked to glycemic control in DM [12, $13,15] . \mathrm{HbAl}_{\mathrm{c}}$ levels above $8 \%$ are suggestive of an increase in the risk of neuropathy [16]. Our study demonstrated a strong relation between ESN, NC frequency and the level of $\mathrm{HbAl}_{c}$, and duration of diabetes as seen in previous studies.

In this study, smoking was significantly associated with ESN $(p<0.05)$ as observed in other studies [17-19]. Smoking increases the frequency of neuropathy by increasing inflammation and endothelial dysfunction. Hence smoking cessation is crucial for good glycemic control [20].

Treatment modality has been associated with the frequency of DSP. Patients treated with insulin have been shown to be associated with a high frequency of DSP, similar to the finding of the present study, probably because patients with type $2 \mathrm{DM}$ were selected and these insulin-treated patients had a longer illness duration.

Carpal tunnel syndrome and DSP are common conditions in patients with diabetes and therefore frequently occur concomitantly as reported by Perkins et al. [21]. In the present study, however, the frequency of the carpal tunnel syndrome (18.5\%) was slightly higher than that reported by Perkins (14\%), but for those with ESN, our value of $13.20 \%$ was lower than that of Perkins (30\%). Considering both reports, it seems that carpal tunnel syndrome is associated with ESN in patients with diabetes although Becker et al. [22] suggested that DM is not a strong risk factor for carpal tunnel syndrome in the Dutch population. Diabetic thoracic radiculopathy is an uncommon complication of DM [23, 24] as evidenced in this study in which diabetic thoracic radiculopathy was found in only $2(1 \%)$ patients with abdominal pain.

The most objective tests for diagnosis of DSP are physical examination, quantitative sensory testing and nerve conduction studies. Nerve conduction studies are the least subjective method compared to others since they are independent of the patient's psychophysical interpretation and they provide reliable, quantitative measures of nerve function. The present study demonstrated that neurologic examinations, determination of NCs and electrophysiologic evaluation are important in the early diagnosis of polyneuropathy and that early EMG examination 
should be done in all diabetic patients, with or without NCs and neuropathic signs.

The main limitation of this study was the inability to accurately determine the duration of DM since the disease often remains undiagnosed for a reasonably long period, thereby influencing the findings.

\section{Conclusion}

The data indicate a strong association between polyneuropathy and smoking, duration of illness, level of $\mathrm{HbA} 1_{c}$, thereby indicating that near normal glycemic control and smoking cessation should be additional precautions to delay the beginning or progression of polyneuropathy.

\section{References}

-1 Brown MJ, Asbury AK: Diabetic neuropathy. Ann Neurol 1984;15:2-12.

-2 Dyck PJ, Giannini C: Pathologic alterations in the diabetic neuropathies of humans: a review. J Neuropathol Exp Neurol 1996;55:11811193.

3 Vinik AI: Diabetic neuropathy: pathogenesis and therapy. Am J Med 1999;107:17-26.

-4 Maser RE, Steenkiste AR, Dorman JS, Nielsen VK, Bass EB, Manjoo Q, Drash AL, Becker DJ, Kuller LH, Greene DA, Orchard TJ: Epidemiological correlates of diabetic neuropathy. Report from Pittsburgh Epidemiology of Diabetes Complications Study. Diabetes 1989;38: 1456-1461.

- 5 de Wytt CN, Jackson RV, Hockings GI, Joyner JM, Strakosch CR: Polyneuropathy in Australian outpatients with type II diabetes mellitus. J Diabetes Complications 1999;13:74-78.

6 Braune HJ: Testing of the refractory period in sensory nerve fibres is the most sensitive method to assess beginning polyneuropathy in diabetics. Electromyogr Clin Neurophysiol 1999; 39:355-359.

7 Oh SJ: Clinical Electromyography: Nerve Conduction Studies, ed 2. Philadelphia, Lippincott Williams \& Wilkins, 1992, pp 87-89.

$\checkmark 8$ Chang C, Lu F, Yang YC, Wu JS, Wu TJ, Chen MS, Chuang LM, Tai TY: Epidemiologic study of type 2 diabetes in Taiwan. Diabetes Res Clin Pract 2000;50(suppl 2):49-59.
Shaw JE, Hodge AM, de Courten M, Dowse GK, Gareeboo H, Tuomilehto J, Alberti KG, Zimmet PZ: Diabetic neuropathy in Mauritius: prevalence and risk factors. Diabetes Res Clin Pract 1998;42:131-139.

10 Kawano M, Omori Y, Katayama S, Kawakami M, Suzuki Y, Takahashi K, Takemura Y, Nagata N, Hiratsuka A, Matsuzaki F, Kanazawa Y, Akanuma Y: A questionnaire for neurological symptoms in patients with diabetes Cross-sectional multicenter study in Saitama Prefecture, Japan. Diabetes Res Clin Pract 2001;54:41-47.

11 Lacomis D: Small-fiber neuropathy. Muscle Nerve 2002;26:173-188.

12 Franklin GM, Shetterly SM, Cohen JA, Baxter J, Hamman RF: Risk factors for distal symmetric neuropathy in NIDDM. The San Luis Valley Diabetes Study. Diabetes Care 1994;17: 1172-1177.

13 Christen WG, Manson JE, Bubes V, Glynn RJ: Risk factors for progression of distal symmetric polyneuropathy in type 1 diabetes mellitus. Sorbinil Retinopathy Trial Research Group. Am J Epidemiol 1999;150:1142-1151.

14 David WS, Mahdavi Z, Nance M, Khan M: Hyperlipidemia and neuropathy. Electromyogr Clin Neurophysiol 1999;39:227-230.

15 Pirart J: Diabetes mellitus and its degenerative complications: a prospective study of $4,400 \mathrm{pa}-$ tients observed between 1947 and 1973. Diabete Metab 1977;3:245-256.

16 Perkins BA, Bril V: Diabetic neuropathy: a review emphasizing diagnostic methods. Clin Neurophysiol 2003;4:1167-1175.
17 Christiansen JS: Cigarette smoking and prevalence of microangiopathy in juvenile-onset insulin-dependent diabetes mellitus. Diabetes Care 1978;1:146-149.

18 Levy LA: Smoking and peripheral vascular disease. Podiatric medical update. Clin Podiatr Med Surg 1992;9:165-171.

19 Mitchell BD, Hawthorne VM, Vinik AI: Cigarette smoking and neuropathy in diabetic patients. Diabetes Care 1990;13:434-437.

20 Eliasson B: Cigarette smoking and diabetes. Prog Cardiovasc Dis 2003;45:405-413.

-21 Perkins BA, Olaleye D, Brill V: Carpal tunnel syndrome in patients with diabetic polyneuropathy. Diabetes Care 2002;25:565-569.

22 Becker J, Nora DB, Gomes I, Stringari FF, Seitensus R, Panosso JS, Ehlers JC: An evaluation of gender, obesity, age and diabetes mellitus as risk factors for carpal tunnel syndrome. Clin Neurophysiol 2002;113:1429-1434.

23 Bertherat J, Netter JM, Timsit J, Chanson P, Blumberg-Tick J, Guillausseau PJ, Warnet A, Lubetzki J: Diabetic thoracoabdominal neuropathy. Clinical and electrophysiological study with evaluation of the autonomic nervous system. Presse Med 1993;22:201-204.

24 Hayes FJ, Redmond JM, McKenna MJ: Thoracic polyradiculopathy - Abdominal wall swelling and sensory symptoms in diabetes mellitus. Ir Med J 1994;87:150-151. 